\title{
Continuidades e Rupturas no Papel da Mulher Brasileira no Século XX
}

\author{
Zélia Maria Mendes Biasoli-Alves ${ }^{1}$ \\ Universidade de São Paulo
}

\begin{abstract}
RESUMO - O século XX, em muitas sociedades, caracteriza-se por movimento de constantes alterações em valores, práticas e papéis; contudo, a literatura tem evidenciado também continuidades em todos esses aspectos. O presente artigo tem como objetivo analisar as mudanças e continuidades no papel da mulher, principalmente no contexto familiar brasileiro, com base em dados de pesquisas realizadas na região sudeste. Os dados são provenientes de entrevistas realizadas com homens e mulheres de diversas faixas etárias, nascidos a partir do final do século XIX até meados dos anos 70. Os resultados enfatizam a nova forma de a mulher ser considerada. A imagem de ser frágil e necessitado de proteção, sob o domínio dos sentimentos, atuando na intimidade e presa aos cuidados com a prole, ganha outros contornos, fazendo dela um ser em construção, na busca de seu desenvolvimento e realização de potencialidades. Os caminhos traçados pela evolução marcam, contudo, continuidades ao lado de rupturas.
\end{abstract}

Palavras-chave: mulher; papel; mudanças e continuidades; século XX.

\section{Continuities and Changes in the Role of Brazilian Woman in the 20th Century}

\begin{abstract}
In many societies, the 20th century is characterized by constant changes in values, practices, and roles. However, the literature has shown the existence of continuities in all of them. The purpose of this article is to analyze changes and continuities in the role of woman, especially in the family context, based on research data collected in the Southeast of Brazil. Data were obtained from interviews carried out with men and women who were born from the end of 19th century until 70's. The results emphasize the new role of woman nowadays. The image of being a fragile, sentimental and caring about her children is replaced by one of a woman in development who seeks to fulfill her potentialities. However, the pathways tracked by the evolution of the role of woman mark both continuities and discontinuities.
\end{abstract}

Key words: woman, role; changes and continuities; 20th century.

Uma das características mais evidentes da Modernidade, no contexto dos países em desenvolvimento, está na oposição entre presente e passado, com uma procura acentuada do novo e a conseqüiente rejeição do antigo. Isto leva a afirmar, sem receio, que no século XX assiste-se a um movimento de constantes alterações em valores, práticas e papéis que as pessoas desempenham, em um número considerável de sociedades. Em tais alterações, é claro o efeito de macrovariáveis como urbanização crescente, avanço da ciência e da tecnologia e necessidades educacionais, tendo como pano de fundo a economia e, mais recentemente, a questão da globalização (Arriagada, 2000). Nesse sentido, há quem diga, com certa freqüência, que se tem que correr atrás de muitos prejuízos, fazendo com que haja uma busca acentuada pelo novo.

Como parte inerente dessas sociedades, a instituição familiar vem sofrendo grandes modificações, interpretadas, ingenuamente, como "crise", como se, em algum outro período, a família tivesse sido essencialmente estável na sua estrutura e nos papéis desempenhados por adultos homens e mulheres, jovens e crianças. Investigações cuidadosas mos-

1 Endereço: Departamento de Psicologia e Educação, Faculdade de Filosofia, Ciências e Letras de Ribeirão Preto - Avenida Bandeirantes, 3900, CEP 14040-901, Ribeirão Preto- São Paulo.

E-mail: zmbiasoli@highnet.com.br tram que isto não se confirma (Ribeiro \& Ribeiro, 1994) e que, por outro lado, em séculos anteriores havia uma preocupação com os rumos que tomavam as relações das pessoas no contexto familiar.

Essas constatações estimularam o nosso interesse em estudar a família, a partir de sua história, analisando, em épocas diferentes, a rotina de vida, os padrões de comportamento adotados por seus membros, sua configuração e modos de funcionamento. Isto se faz necessário, uma vez que, para compreender o presente, é importante (para não dizer necessário) que se conheça as normas e práticas do passado e as transições que foram ocorrendo, em diferentes períodos (Burke, 1991). Portanto, dois aspectos devem ser considerados: as mudanças e as continuidades. Às vezes, práticas e atitudes parecem assumir apenas e tão somente uma outra roupagem, mostrando, numa análise mais aprofundada, que a maneira de pensar certas questões ainda se encontra presa aos padrões de outras épocas.

Contudo, há autores como Gundelach (1991), que ao discutirem alterações em atitudes e padrões comportamentais ocorridos ao longo do século XX, na maioria das sociedades, sobretudo as consideradas "civilizadas", afirmam ter havido uma substituição radicalizada dos valores autoritários pelos libertários. Tal substituição é, muitas vezes, atribuída a mudanças fortemente influenciadas pelo aumento no nível geral de escolarização das gerações mais novas. Portanto, o 
processo de influências bidirecionais e as condutas recém adquiridas geram novas modificações, produzindo atitudes que serão vetores para a concretização de outros valores, em ciclos que se repetem continuamente.

A argumentação deste autor (Gundelach, 1991) permite que se levante como hipótese que a um período de maior "turbulência", em que alterações drásticas estão presentes, caracterizando quase que um rompimento com o certo e o errado vigentes, suceda um outro tempo de busca por maior equilíbrio. Isto ocorre quer porque os efeitos das mudanças são avaliados e "corrigidos nos seus excessos", quer porque, como processo, ele admite uma constante, um movimento que se perpetua sempre, provocando o aparecimento de novas formas de lidar com as situações que, por sua vez, também já se modificaram.

Nesse sentido, para pesquisar "família", além de traçar a evolução histórica, descrevendo os valores presentes em momentos diversos, seria fundamental buscar acrescentar o contexto de cada época, de tal forma a estruturar um quadro que inclua os ambientes imediato, mediato e as trocas estabelecidas entre os contextos micro, meso, macro e exo, conforme modelo proposto por Bronfenbrenner (1994), como suporte para uma análise de dados adequada. Mas, é importante ressaltar que o tema "família" é por demais amplo e que um recorte precisa ser estabelecido, tanto no tempo abrangido, quanto no sujeito foco da análise. Portanto, neste artigo, o conteúdo tem como base os dados sobre a mulher de camada média e popular da sociedade brasileira do final do século XIX à década de 90 do século XX, com especial atenção à educação que ela recebia e ao seu papel dentro do ambiente doméstico.

Sem buscar fazer uma "História das Mulheres", que é um campo que tem suas regras e características bem definidas desde as décadas de 70 e 80 e tem as mulheres como objeto de estudo, sujeitos da História (Scott, 1992, p. 77), objetiva-se, aqui, retomar relatos obtidos através de entrevistas que fazem parte de diferentes projetos de pesquisa e, a partir deles, estabelecer reflexões sobre mudanças e continuidades na educação, no comportamento e no papel da mulher, quer quando idealizado quer concretizado nas tarefas a ela atribuídas, no dia a dia da vida familiar.

Para cumprir o objetivo a que se propõe, parte-se de um banco de dados que tem por base relatos obtidos em entrevistas feitas no estado de São Paulo, com idosos/idosas e mulheres/homens de meia idade, todas $(n=20)$ realizadas num formato semi-estruturado, dentro do Projeto Integrado "Família e Socialização - Processos, Modelos e Momentos no Contato entre Gerações" ${ }^{2}$, buscando compor Histórias de Vida Temáticas ${ }^{3}$.

Os procedimentos para identificação dos informantes foram diferentes e adaptados às características de cada estu-

2 Projeto apoiado pelo CNPq, Processo No. 350084/93-9

3 História de Vida Temática consiste em uma estratégia em que o pesquisador, tomando por base a seqüência de eventos da história do informante, seleciona os temas que têm interesse especial para o seu projeto e investiga-os mais detalhadamente. do. Ora se recorreu a instituições para idosos, tendo-se acesso a um fichário que possibilitou a seleção da amostra de acordo com critérios pré-estabelecidos de idade, sexo e condições sociais, ora se obteve nomes e endereços, a partir de conhecimento pessoal dos pesquisadores envolvidos no projeto. O passo seguinte consistia em consultar a amostra selecionada quanto ao interesse em participar; havendo concordância, as entrevistas eram agendadas segundo a disponibilidade das pessoas contatadas. Não havia limite de tempo, sessões ou assuntos ao se entabular as conversas e cada informante era entrevistado sozinho, sendo gravadas todas as sessões. Transcrições, na íntegra, foram feitas e conferidas, havendo, no momento, acúmulo de um material extenso e rico, o que possibilita análises diversas.

Para o presente trabalho, selecionou-se: (a) um conjunto de entrevistas com pessoas idosas $(n=12)$, de mais de 70 anos, de ambos os sexos, residindo com a família e possuindo independência financeira advinda de pensão ou aposentadoria; (b) um conjunto de entrevistas com mulheres na faixa de $40-50$ anos $(n=8)$, mães, parte com atividade profissional e parte não, a maioria casada e residindo com o marido, no momento da coleta de dados.

A análise qualitativa de dados pautou-se na proposta de Biasoli-Alves e Dias da Silva (1992), que descreve os passos para se proceder à captação do significado presente na fala dos informantes, mantidos os limites do tema focalizado. Os resultados apresentados, a seguir, priorizam cada um dos períodos identificados como marcos na evolução de diferentes gerações e, neles, alguns aspectos descritivos da educação da mulher e de seus papéis na vida familiar.

\section{Os valores e sua forma de transmissão: de 1890 a 1930/40}

A observação do relato de idosos/idosas que passaram a infância no final do século XIX e início do XX evidencia um conjunto de valores presentes, de forma maciça, em diferentes camadas da população (médias e populares); alguns aplicar-se-iam indistintamente ao menino e à menina: "Respeito", "Obediência", "Honestidade", "Trabalho"; mas outros seriam apenas ligados ao contingente feminino: "Submissão", "Delicadeza no Trato", "Pureza", "Capacidade de Doação", "Prendas Domésticas e Habilidades Manuais". Esses valores recebem o rótulo de tradicionais $^{4}$, e cada grupo mostra, claramente, o que é esperado de um menino/rapaz e o que vem a ser o desejável para uma menina/moça. Ou seja, a educação não só se fazia diferente quanto propiciava que as distinções ficassem bem marcadas.

E como é que as famílias lidavam com as crianças e transmitiam tais valores às gerações mais novas? Qual a forma de conseguir com que tais valores fossem aceitos e estivessem presentes no comportamento das meninas, moças e mulhe-

4 Essa denominação procura marcar a diferença com os padrões comportamentais desejáveis que a Modernidade trouxe. 
res? Que prática de educação garantia o sucesso do que os pais pretendiam?

A análise dos relatos obtidos nas entrevistas com mulheres de mais de 50 anos (idosas e de meia idade), independentemente das diferenças entre camadas sociais (condições econômicas e educacionais), mostra que o processo de socialização empregado pelos adultos, para estabelecer o controle sobre o comportamento, imprime, desde cedo, na menina, a auto-restrição. Fatores essenciais estão presentes numa prática que gera, além de disposição para obedecer, um conhecimento claro do que é certo e do que é errado, bem como a capacidade de se auto conter. Primeiramente, a existência de laços estreitos entre adultos significativos e a criança. Segundo, um "vigiar" constante que permite poucas oportunidades para a quebra das regras. Terceiro, existem punições severas para tudo o que é considerado como "indesejável", incluindo-se os excessos de "surras e cascudos". Contudo, o controle sobre a menina é exercido, mais freqüentemente, por meio de:

1. Ameaças de retirada de afeto. Ex.: Você age assim e ninguém gosta... (Mulher, 78 anos)

2. Ameaças de abandono e solidão. Ex.: Moça assim não casa... (Mulher, 80 anos)

3. Castigo dos Céus. Ex.: Nossa Senhora está olhando para você e está triste... (Mulher, 90 anos)

4. Remorço. Ex.: Quando eu morrer, você vai ver a falta que vou fazer...e aí vai ser tarde demais. (Mulher, 75 anos)

5. Culpa. Eu só quero o seu bem.... o seu pai também... o que você está fazendo é uma ingratidão... (Mulher, 90 anos)

Analisar o processo de educação da criança na família sob este ângulo permite visualizar a sua completude face ao tipo de comportamento mais valorizado para a menina, na sociedade do final do século XIX e primeiras décadas do século XX, qual seja, a "Obediência" aos mais velhos e às regras do grupo familiar (Herbert, 1987; Biasoli-Alves, 1995). Tratava-se de um sistema em que a possibilidade de que a menina/moça/mulher viesse a transgredir e sentisse $o$ "gosto bom" da liberdade era muito restrita. Restava-lhe o prazer de "agradar"; porque aí passava a ouvir elogios: $E u$ sempre agradei quando fazia a coisa certa, eu dizia que ficava bonita, que agora sim era uma mocinha... (Mulher, 80 anos). E todos diziam aos pais que eles estavam de parabéns, porque nada me dava mais prazer do que, quando saia com eles, ouvir alguém elogiar e falar: 'nossa, que menina mais educada que você tem, é um primor esta sua filha'. (Mulher, 90 anos)

Portanto, os pais estavam cumprindo muito bem o seu papel, moldando à perfeição a sua prole, custasse quanto custasse. No entanto, quando se desloca o foco da observação, somos forçados a indagar o que havia por trás desse processo de educação da menina. É certo que alguns estarão olhando o fenômeno e afirmando que se tratava apenas do lado complementar (e, portanto, fundamental) do "Domínio", a ser exercido pelo homem, cuja educação era diversa daquela da mulher, em muitos aspectos. Como se poderá ter
"Domínio" se não houver "Submissão", papel por excelência da mulher, ainda no decorrer de boa parte do século XX? Mas, talvez se possa explicar esse binômio na maneira de lidar com o menino e a menina de um ponto de vista mais social e econômico. Existe uma preocupação com o "futuro da moça", que precisará "arranjar" um marido (provedor) e que, para tal, terá as suas "virtudes", todas, muito "olhadas" e seriamente investigadas, sobretudo se for para "fazer um bom casamento", com um rapaz considerado um "bom partido".

\section{A educação escolar e o contexto social}

O fato de que a moça precisa ter características tais que a tornem "desejável" como esposa cria uma teia complexa, tão intrincada que as práticas tendem a se perpetuar e a se reproduzir nas mais diversas famílias que têm "filhas mulheres". Contudo, não basta possuir os atrativos necessários e a atenção de candidatos porque, em última instância, é a família quem tem o poder, quem "arranja" os casamentos, ou são as famílias que se juntam e combinam o que para elas é considerado o melhor.

No final do século XIX e início do XX "a mulher é escolhida", ao mesmo tempo em que é "comandada". Moça com muitos pretendentes tinha os seus pais e irmãos para direcionarem (com brandura ou imposição) com quem deveria se casar. E, por isso, não precisava estudar, porque, segundo as mulheres e os homens mais velhos, era dito, como justificativa para tirar a menina da escola que:

O estudo muda a cabeça e faz a moça ficar sonhando bobagens. (Mulher, 80 anos)

Mulher aprende a ler e escrever só pra ficar lendo romances e escrevendo bilhetes para o namorado. (Homem, 78 anos)

Moça direita não perde tempo com essas besteiras de ficar lendo romances, porque isto é ocasião de perdição. (Mulher, 75 anos)

Na verdade, não se quer que ocorram mudanças; não se quer ter trabalho para "convencer a filha do que é melhor para ela" ou de qual é "o seu dever frente aos pais que a criaram com tanto zelo". Por outro lado, analisando o contexto da época e olhando a História da Educação no Brasil, nas primeiras décadas do século $\mathrm{XX}$, pode-se verificar que havia poucas Faculdades no país; somente nos grandes centros, sobretudo no eixo Rio-São Paulo (Almeida, 2000). No entanto, existiam muitos colégios, a maioria confessionais, herança dos Jesuítas, mas também de outras congregações religiosas que para cá vieram, cada qual trazendo os seus padres e suas freiras, preocupados em educar para Deus e a sociedade, "os filhos e filhas da terra".

Proliferam, então, os colégios para meninos e meninas das classes abastadas e torna-se cada vez mais comum que a "moça de família", depois que aprendeu em casa as "primeiras letras", seja enviada a um colégio interno de freiras "para ser educada". De lá ela sairá depois de alguns anos, pronta para casar. E o que lhe foi ensinado? A fala de um dos entrevistados é muito clara a este respeito: 
Porque minha mãe tinha curso de culinária... foi estudante durante muito tempo em colégio de freira... de maneira que ela saiu de lá habilitada... bordava, tocava piano, cozinhava... era boticária minha mãe. Se hoje ela tivesse viva... eu até brincava com ela... porque ela tinha garrafada curtindo no álcool... pra tudo quanto é doença... (Homem, 78 anos)

Talvez se deva salientar, mais uma vez, que, se de um lado, os valores eram importantes, havia então uma prática capaz de fazer com que eles acontecessem. E é essa prática tão em consonância com o que a educação pretendia que surpreende pela sua eficácia e abrangência. A sociedade estratificada, econômica e culturalmente, mantém-se sem muitos atropelos e se costuma dizer, de uma ou outra mulher, por razões diversas, que "ela sabe qual é o seu lugar". Ou seja, seu domínio restringe-se ao seu lar. É do marido, dos filhos e dos pais (sogros, tios, tias) idosos que ela deve se ocupar.

Neste contexto, a religião desempenha um papel importante, sobretudo para a manutenção dos valores vigentes, na medida em que acrescenta restrições e temores (sobrenaturais) ligados às conseqüências do "Pecado da Desobediência”, que não só leva ao inferno mas transtorna toda a vida e atrai desastres e miséria como "Castigo Divino". Em outras palavras, o discurso da religião (com predomínio quase absoluto da Católica, até a década de 60) apenas confirma e enfatiza o que a família está dizendo, ou seja, as restrições são no mesmo sentido e se reforçam.

\section{Meados do século XX: valores e primórdios da profissionalização}

Após duas ou três décadas, esses valores desapareceram? Foram substituídos por outros? Ou foram mantidos de forma "encoberta" enquanto a mulher conquistava o direito à escolarização e a exercer atividades profissionais? A resposta mais provável é: foram mantidos. Os dados de nossos projetos permitem afirmar que, durante todo um período que se poderia classificar como de transição, há um "pano de fundo" contra o qual a mulher continua sendo avaliada, ainda que a análise do quadro que se desenha nos anos 30, 40 e 50 mostre, já, uma abertura maior para a sua escolarização. No entanto, as diferenças permanecem muito grandes entre as expectativas da família em relação à vida escolar e profissional de seus "filhos homens" e a das meninas/moças. É usual ainda que, por motivos que hoje se diria serem pequenos, a filha seja retirada da escola e posta em casa "para ajudar". Também se decide por interromper seus estudos ou trabalho "para que ela se prepare para o casamento", que pode estar ocorrendo antes dos 18 anos, desde que o noivo tenha condições financeiras favoráveis e a família o veja como "um ótimo partido". É importante que se acrescente uma outra razão poderosa para isto, a de que a união precoce aliviava os adultos (e mesmo os irmãos menores) da tarefa de "tomar conta" da moça, sobretudo porque ela deveria se manter virgem até o casamento e, para tal, a responsabilidade era de cada um e de todos, deixando perpassar a idéia de que a mulher era vista como frágil, ingênua e passível de ser influ- enciada. As tentações, nunca se sabe, né, quando vão aparecer... (Homem, 82 anos)

Também se observa que, com raras (e muitas vezes criticadas) exceções, a mulher prioriza a sua vida doméstica, mesmo tendo conseguido obter um diploma (universitário) e um emprego, deixando tudo de lado quando se casa ou chegam os filhos, o que evidencia o papel principal do homem dentro da família, que é o de provedor de todas as necessidades materiais. Este comportamento "de renúncia" por parte da mulher é valorizado; sendo dever dela "se dedicar aos seus".

São muitas e sérias as perguntas que este quadro suscita. Por exemplo, porque a mulher conquista, nessa época, o direito à escolarização? Como estavam sendo dirigidas, nesse período, as práticas de cuidado e de educação da menina? Primeiramente, poder-se-ia indagar de onde partiu a mudança. Teria acontecido, em diferentes lugares, uma luta aberta, em que meninas e moças pegaram bandeiras e foram para a praça clamar por liberdade, autonomia e possibilidades de profissionalização? Ou seriam outros os fatores associados? Ou, talvez, quem sabe, uma mescla de tudo isto?

Uma análise de alguns aspectos da vida numa sociedade, que aceleradamente se torna urbana e com muitas mudanças, leva a identificar, como subjacentes às alterações no papel e nas atividades femininas, certos fatores que não estavam diretamente sob o seu domínio. A realidade mostra uma estrutura da economia anterior desfazendo-se e, aos poucos, sendo substituída por outra, que passa a "exigir da mulher mais habilidades além das que já vêm de berço". Ela precisa, agora, ser capaz também de aprender a gerir salários (fazer contas) e a cuidar de que os filhos (homens, sobretudo) dominem as tarefas da escola. Ela está "aquém, muito aquém" de tais habilidades, mas percebe-se como importante que ela domine a leitura e a escrita, de modo consistente (Caldana, 1998). Isto, não porque ela seja um sujeito de direitos e deva lhe ser assegurada a igualdade, mas porque se espera dela competências que melhor promovam a educação dos filhos e a própria vida doméstica, que façam dela o suporte adequado para o sucesso profissional de seu esposo.

Era uma época em que a sociedade caracterizava-se por um forte predomínio da vida na cidade, o que não impedia se encontrasse muitas famílias extensas em que, até três a quatro décadas atrás, as várias gerações mantinham uma convivência diuturna. E, lembrando que as mulheres costumavam viver mais do que os homens (como acontece ainda hoje), são as avós, as mães e as filhas que partilham um mesmo espaço e constroem um cotidiano. Neste, com as alterações nas formas de pensar e agir, os conflitos marcam presença, com críticas abertas ou veladas de mães para com suas filhas, avós para com netas e vice-versa. Apesar do contato constante, a separação em termos dos valores passa a ser bem notada, num período em que fazer face ao passado, negar a partilha de um conjunto de atitudes, práticas e normas era o mesmo que se declarar "moderno". E a mulher estava no meio desta "revolução", conduzindo o processo mais do que se deixando levar.

$\mathrm{Na}$ educação das meninas, as estratégias das mães para lidar com a sua prole eram similares às de épocas ante- 
riores, embora elas estivessem muito preocupadas em "não repetir os erros do passado".

Aquilo que a minha mãe fazia comigo e com os meus irmãos, de forçar a gente a cumprimentar todo mundo, a ir à missa no domingo cedinho, eu não queria nunca para a minha filha... então eu fiz mesmo diferente! (Mulher, 50 anos)

Elas questionavam, freqüentemente, o "excesso de rigidez", a "autoridade", o "nível de exigência" e a "punição" que fizeram parte da sua educação, as muitas oportunidades que perderam e o quanto era importante mudar a forma de agir para que os filhos tivessem uma vida mais saudável. Por outro lado, alguns outros aspectos também sofreram alterações: As "surras" são menos freqüentes e a figura do pai passa por "certo abrandamento" no que diz respeito à autoridade, ainda que continue um pouco distanciada dos cuidados cotidianos. Entretanto, permanece um clima em que predomina um controle da menina (às vezes, também do menino), por meio de estratégias emocionais, tentando fazer dela uma moça que seja socialmente bem aceita.

Portanto, abrem-se possibilidades de um crescimento diverso do que caracterizou as gerações precedentes, mas, ao mesmo tempo, há limites quanto ao que seria excesso e ao que seria visto como inversão de papéis. Com relação a este aspecto, é importante enfatizar que a Família e a Igreja ainda estão falando uma linguagem muito próxima, e pretendem continuar dizendo o que é certo e o que é errado, o que se pode considerar como um bom comportamento e o que é inaceitável para "uma moça de família". No entanto, percebe-se uma "diminuição na rigidez das normas, um começo de encantamento com a inteligência, a competência, o trabalho e a independência da filha", resguardado o valor atribuído ao "casamento com a pessoa certa, a obediência a padrões de moralidade estabelecidos e mantidos através de gerações". Por exemplo, seria bom se ela tivesse algo com que se virar porque, hoje em dia, ninguém sabe... é tudo tão incerto... nem o casamento garante... (Mulher, 48 anos)

Da escolarização à profissionalização, há um caminho longo, ao mesmo tempo que natural. As pressões econômicas que a modernidade trouxe, as heranças que não mais se sustentaram, a "quebradeira" que aconteceu depois de 1929 constituíram fatores importantes na determinação da alteração da perspectiva relativa ao trabalho da mulher. E é a família que, no meio urbano, cada vez mais se torna permeável às pressões do mundo ao seu redor, sofre as transformações acentuadas na sua estrutura e cotidiano, mas também colabora para que outras mudanças, advindas de suas novas necessidades, aconteçam no âmbito do social.

\section{As últimas décadas do século XX}

A maior escolarização e a profissionalização da mulher acarretaram um contato social mais amplo e constante; como conseqüência, o questionamento se intensificou e atingiu muitas áreas. Os seus efeitos estão presentes até hoje. Isto significa existir um descontentamento com o passado, uma análise depreciativa de como as mulheres eram criadas, da sua submissão, dos limites estreitos impostos ao seu movimento dentro dos grupos sociais e às possibilidades de escolha profissional. Todos esses aspectos aparecem na discussão, quer de grupos feministas quer de outros que passam a enfatizar o excesso de trabalho que recai sobre a mulher que, agora, mantém atividades fora do lar, mas ainda é a responsável pelo bom andamento da casa, dos filhos e do bemestar do marido. É como se um caldeirão estivesse no fogo, pronto para entrar em ebulição a qualquer momento.

Assim, a transformação pode ser vista como acelerada e também lenta, na dependência do referencial temporal que se utiliza. Nessa ótica, pode-se afirmar que valores tradicionais como "Respeito", "Obediência", "Submissão", "Delicadeza no Trato", "Pureza", "Capacidade de Doação" e "Habilidades Manuais", que foram considerados atributos fundamentais e definidores da "boa moça" até meados do século XX, são "passados para trás", o que significa "deixar de estar na linha de frente" da educação da menina/moça, permanecendo, sem dúvida, de forma "encoberta", enquanto a mulher conquista o direito à escolarização e a exercer atividades profissionais diversificadas.

Dentre os outros aspectos a serem mencionados, é importante ressaltar a educação para cada um dos sexos. Dados de uma pesquisa de Biasoli-Alves (1995) mostram, de modo inequívoco, que os meninos, na década de 80, ainda estavam muito mais sujeitos a serem fisicamente punidos, diferentemente do que acontecia com as meninas, que eram mantidas mais próximas de suas mães e submetidas a um controle emocional, o que pode ser constatado através das seguintes falas: ... que coisa mais feia! (Mulher, 43 anos), ... o que eu fiz, mеи Deus, para merecer... (Mulher, 48 anos); ... a gente te dá tudo o que você pede e ainda assim nada está bom... (Mulher, 50 anos)

Por outro lado, as mães relataram que perdem a paciência, gritam e, se a criança não obedece, elas fazem algum tipo de ameaça. Os dados evidenciam que elas, hoje, mostram-se mais irritadas e apressadas e querem que o filho cumpra seus compromissos, sem trazer muitas dificuldades para um cotidiano já conturbado. Também, não se pode negar que, de meados da década de 70 em diante, está-se frente ao fenômeno da grande incerteza e insegurança dos pais quanto a melhor maneira de educar os filhos. Não se trata agora da preocupação de que eles sejam "bem educados", "respeitadores dos mais velhos" para que a família receba elogios; a preocupação gira em torno do "vir a ser", do futuro e das consequiências negativas de certas práticas de cuidado e educação (Biasoli-Alves, Caldana \& Dias da Silva, 1997).

Pode-se, então, assumir que houve alterações drásticas e que o questionamento que subsistiu, em boa parte do século $\mathrm{XX}$, fez com que certos valores chegassem até à negação enquanto outros adquirissem maior relevância, levando a mulher a se distanciar do ideal anteriormente pregado. Destacam-se mudanças acentuadas nos seguintes aspectos:

1. No espaço em que era (e é agora) permitido que a mulher transitasse. Depois da década de 30, quando ela nem podia sair à rua para fazer compras, a não ser que estivesse acompanhada por uma pessoa mais velha, por uma 
criada, ou pelo próprio marido, o direito de ir e vir vai surgindo e cada vez se tornando maior, sendo poucos os ambientes (se comparados com o que acontecia antes) em que existe a proibição ou a não recomendação de sua presença.

2. No trabalho. A mulher parte da casa, do trabalho doméstico ou atrelado aos adultos da família (em especial, na zona rural) e à igreja e se profissionaliza; ela alcança, na atualidade, postos elevados e importantes em muitas sociedades. Predomina, pois, o sentido de liberdade e a diminuição das interdições.

3. No casamento. Este é um tópico que vale a pena retomar e dar continuidade à descrição da sua evolução, porque as razões e condições que levam as mulheres ao casamento parecem traçar um caminho nítido de mudanças, do final do século XIX às décadas de 80/90 do século XX.

\section{O casamento e sua evolução}

Os dados extraídos dos relatos de mulheres, hoje com 80 ou 90 anos, referindo-se quer ao seu namoro e casamento, quer à forma como foi realizada a união de seus pais, não deixam dúvidas quanto ao fato de que nos idos de 1900 havia pouca permissão para uma decisão pessoal. A(s) família(s) de origem definiam com quem, como e quando as moças e rapazes deveriam se casar. Nos poucos casos em que as regras foram infringidas e os jovens se opuseram à vontade dos pais, houve ruptura das relações e o casal foi excluído do círculo de convívio familiar.

Nas décadas de 30 e 40, observa-se, nas descrições feitas, que a ingerência era a regra. As moças conheciam seus futuros maridos através dos pais e acatavam sua opinião, aceitando uniões que satisfaziam os critérios colocados pelos mais velhos, que definiam o que seria um "bom casamento". Há, também, um conjunto claro de "virtudes" valorizadas, capazes de tornar a jovem "desejável" para esposa dos filhos de "boa família".

O passo seguinte, já nas décadas de 50 e 60, é representado pela aprovação ou não de escolhas feitas a partir de um conhecimento de pares, começando a sair do domínio exclusivo da família de origem. Pais e irmãos não são mais a fonte direta e quase exclusiva de abertura para a vida social mais ampla; as cidades crescem e mudam as possibilidades de a família "conhecer todo mundo"; um contingente significativo de mulheres está, neste momento, conquistando o direito de ir para a universidade, o que, muitas vezes, exige mudar de cidade e morar fora da casa paterna, uma vez que as poucas opções estão nos grandes centros.

Chega-se, então, gradativamente, ao momento em que a "escolha é livre", num movimento que inverte a direção: os pais devem aceitar o que a geração mais nova determinou para si mesma; não são mais eles que podem dizer "eu sei o que é melhor". Os filhos afirmam que eles, e tão somente eles, têm o poder e o direito de saber com quem querem conviver, talvez, para o resto de seus dias, mas muito provavelmente não para sempre.
As últimas décadas ficam também marcadas pelo aumento no número de separações, divórcios e recasamentos, implicando numa exigência de mudança nas definições do que é ou não valorizado na mulher (ainda que, muitas vezes, apenas aparentemente); mas, sobretudo por uma negação da formalização das uniões, pelo menos durante uma fase inicial de convivência, acontecendo o casamento civil após o nascimento de um filho.

Entretanto, se, por um lado, há alterações, por outro, há aspectos em que não se percebe tão claramente que a direção seguida, hoje, seja oposta a de décadas atrás. Um exemplo típico diz respeito ao papel da mulher dentro do ambiente familiar. Na verdade, observa-se que mudam algumas palavras: - casa ao invés de lar, mulher ao invés de esposa, o que parece indicar quer a rejeição das amarras, quer a luta, agora sim, muito mais direcionada, da mulher para se posicionar frente ao mundo masculino-feminino. Nessas rupturas com o passado, contudo, ao fazer face a um processo consolidado em muitas décadas, sobrou para a mulher, ainda, o "sentimento de culpa" que aparece a cada vez que "a criança fica doente...", "os pais precisam de seus cuidados...", "o casamento vai mal..."

\section{Considerações finais}

Analisar, levantar críticas e buscar compreender, construindo uma visão melhor do que se passa, hoje, quer se esteja olhando a educação dada à menina no ambiente familiar, quer se discuta o papel que é atribuído a cada um dos membros do casal, não é tarefa que se esgote em um único estudo. Ao proceder assim, corre-se o risco de fazer uma descrição de tal natureza que se crie a ilusão de que a mulher do final do século XX é inteiramente diferente da de 80 ou 100 anos atrás. Ilusão porque essa alteração completa, nesse espaço de tempo - um século apenas - teria poucas chances de acontecer.

Como ser social que é, o homem faz parte de uma espécie que evoluiu como gregária, cujos filhotes nascem preparados para serem socializados através dos adultos que os geraram, isto é, para adquirirem os padrões, valores e normas do grupo social no qual estão inseridos. Isto implica em que a construção da identidade do ser humano se dá no contexto social, através de um processo de olhar para o outro e estabelecer comparações, formando uma subjetividade que contém e contempla a forma como se é visto (Velho, 1987). Portanto, os valores dos adultos significativos começam a ser assimilados quando ainda a criança nem aprendeu a falar direito, estabelecendo que ela será socializada para se tornar um adulto dentro daquela cultura. No dizer de Brandão (1981),

cada um de nós passa por etapas sucessivas de inculcação de tipos de categorias gerais, parciais ou especializadas de saber e habilidade... que fazem, em conjunto, o contorno da identidade, da ideologia e do modo de vida de um grupo social... e fazem também, do ponto de vista de cada um de nós, aquilo que aos poucos somos, sabemos, fazemos e amamos". (p. 23) 
São exatamente essas etapas sucessivas de inculcação que não permitem um afastamento total do que veio sendo composto. Os valores acham-se entranhados na cultura e sua assimilação é lenta, constante e profunda, de tal modo que transformações drásticas levam muito tempo para se efetivarem. Além disso, para que isto ocorra, as gerações precisariam não manter contato umas com as outras; $\mathrm{e}$, numa sociedade que envelhece também rapidamente, estão convivendo, na mesma família, os bisavós, os avós, os filhos e os netos, negando, assim, a descontinuidade do processo de transmissão de padrões, valores e normas.

Mesmo que se admita que a evolução social trouxe, com certa frequiência, o afastamento das famílias de origem, em que as gerações mais novas foram (e são) "deixadas por sua conta e risco", diminuindo e até desaparecendo a ingerência na vida dos casais jovens e, também, a possibilidade de conversa e troca de experiência com as mulheres das gerações mais velhas (Biasoli-Alves, 1997; Doumanis, 1983; Gundelach, 1991), é preciso levar em conta o que dizem Scabini e Marta (1996). Para elas, a família psicológica é sempre uma família extensa, tendo, os ancestrais, uma influência muito forte na formação das demais gerações.

Por esta razão (e outras) é que não se pode responder afirmativamente à questão: Aconteceram só rupturas? Obviamente não; há muitas continuidades a serem consideradas. Os valores que os mais velhos cultivaram e buscaram imprimir nos seus filhos e netos estão ainda presentes, hoje, mesmo que sob outras "roupagens". Tais continuidades ocorrem, mesmo que se tenha observado que a imagem da mulher, "ser frágil e necessitado de proteção, sob o domínio dos sentimentos (do nervosismo), atuando na intimidade e presa aos cuidados com a prole, ganha outros contornos que fazem dela um ser em construção, na busca de seu desenvolvimento e da realização de suas potencialidades". Há muitas outras questões importantes para serem analisadas e vários ângulos por considerar, principalmente com base no binômio “domínio versus submissão", embora isto não combine com a ideologia subjacente de buscar fundamentalmente igualdade, dentro e fora do relacionamento familiar.

\section{Referências}

Almeida, J.R.P. (2000). Instrução pública no Brasil (1500-1889): história e legislação. (A. Chizzotti, Trad.) São Paulo: EDUC, COM, PED e INEP. (Trabalho original publicado em 1989)

Arriagada, I. (2000). Nuevas Famílias para um nuevo siglo? (Relatório publicado pela Comisión Econômica para América Latina y el Caribe). Chile: CEPAL.

Biasoli-Alves, Z.M.M. (1995). Família, socialização e desenvolvimento: as práticas de educação da criança. Tese de Livre Docência, Universidade de São Paulo, Ribeirão Preto.

Biasoli-Alves, Z.M.M. (1997). Famílias brasileiras do século XX: os valores e as práticas de educação da criança. Temas em Psicologia, 3, 33-49.

Biasoli-Alves, Z.M.M., Caldana, R.H.L. \& Dias da Silva, M.H.G.F. (1997). Práticas de educação da criança na família: a emergên- cia do saber técnico-científico. Revista Brasileira de Crescimento e Desenvolvimento Humano, 7, 49-62.

Biasoli-Alves, Z.M.M. \& Dias da Silva, M.H.G.F. (1992). Análise qualitativa de dados de entrevista. Cadernos de Psicologia e Educação Paidéia, 1, 61-69.

Brandão, C.R. (1981). O que é educação? São Paulo: Brasiliense.

Bronfenbrenner, U. (1994). Ecological models of human development. Em T. Husten \& T.N. Postelethwaite (Orgs.), International encyclopedia of education ( $2^{\text {nd }}$ ed., Vol. 3, pp.1643-1647). New York: Elsevier Science.

Burke, P. (1992). Abertura: a nova história, seu passado e seu futuro. Em P. Burke (Org.), A escrita da História: novas perspectivas (pp.7-37). São Paulo: Editora UNESP.

Caldana, R.H.L. (1998). Ser criança no começo do século: alguns retratos e suas lições. Tese de Doutorado, Universidade Federal de São Carlos, São Carlos.

Doumanis, M. (1983). Mothering in Greece: From collectivism to individualism. New York: Academic Press.

Gundelach, P. (1991). Panorama des changements valeurs recents em Europe Occidentale. A New Europe de Base, 2, 3-27.

Herbert, M. (1987). Conduct disorders of childhood and adolescence: A social learning perspective. Chichester: Wiley.

Ribeiro, I \& Ribeiro, A.C.T. (1994). Família e desafios na sociedade brasileira: valores como ângulo de análise. Rio de Janeiro: Centro João XXIII.

Scabini, E. \& Martas, E. (1996). Family with late adolescents: Social and family topics. Em M. Cusinato (Org.), Research on family resources and needs across the world (pp. 177-197). Padova: Edizioni Universitarie di Lettere Economia.

Scott, J. (1992). História das Mulheres. Em P. Burke (Org.), A escrita da História: novas perspectivas (pp.63-95). São Paulo: Editora UNESP.

Velho, G. (1987). Individualismo e cultura. Rio de Janeiro: Jorge Zahar Editor 